\title{
openheart Absence of chest pain and long-term mortality in patients with acute myocardial infarction
}

\author{
Lena Björck, ${ }^{1,2}$ Susanne Nielsen, ${ }^{1}$ Tomas Jernberg, ${ }^{3}$ Tatiana Zverkova-Sandström, ${ }^{1}$
} Kok Wai Giang, ${ }^{1}$ Annika Rosengren ${ }^{1,2}$

\begin{abstract}
- Additional material is published online only. To view please visit the journal online (http://dx.doi.org/10.1136/ openhrt-2018-000909).
\end{abstract}

To cite: Björck L, Nielsen S, Jernberg $\mathrm{T}$, et al. Absence of chest pain and long-term mortality in patients with acute myocardial infarction. Open Heart 2018;5:e000909. doi:10.1136/ openhrt-2018-000909

Received 23 July 2018 Revised 3 0ctober 2018 Accepted 10 November 2018

D Check for updates

(c) Author(s) (or their employer(s)) 2018. Re-use permitted under CC BY-NC. No commercial re-use. See rights and permissions. Published by BMJ.

1 Department of Molecular and Clinical Medicine, Sahlgrenska Academy, University of Gothenburg, Gothenburg, Sweden

${ }^{2}$ Department of Medicine, Sahgrenska University Hospital/ Östra Sjukhuset, Gothenburg, Sweden

${ }^{3}$ Department of Clinical

Sciences, Danderyd Hospital, Karolinska Institutet, Stockholm, Sweden

Correspondence to Dr Lena Björck; lena.bjorck@ gu.se

\begin{abstract}
Objective Chest pain is the predominant symptom in patients with acute myocardial infarction (AMI). A lack of chest pain in patients with AMI is associated with higher in-hospital mortality, but whether this outcome is sustained throughout the first years after onset is unknown. Therefore, we aimed to investigate long-term mortality in patients hospitalised with AMI presenting with or without chest pain.
\end{abstract}

Methods All AMI cases registered in the SWEDEHEART registry between 1996 and 2010 were included in the study. In total, we included 172981 patients (33.5\% women) with information on symptom presentation. Results Patients presenting without chest pain (12.7\%) were older, more often women and had more comorbidities, prior medications and complications during hospitalisation than patients with chest pain. Short-term and long-term mortality rates were higher in patients without chest pain than in patients with chest pain: 30day mortality, 945 versus 236/1000 person-years; 5-year mortality, 83 versus $21 / 1000$ person-years in patients $<65$ years. In patients $\geq 65$ years, 30-day mortality was 2294 versus 1140/1000 person-years; 5-year mortality, 259 versus $109 / 1000$ person-years. In multivariable analysis, presenting without chest pain was associated with an overall 5-year HR of 1.85 (95\% Cl 1.81 to 1.89), with a stronger effect in younger compared with older patients, as well as in patients without prior AMI, heart failure, stroke, diabetes or hypertension.

Conclusion Absence of chest pain in patients with AMI is associated with more complications and higher shortterm and long-term mortality rates, particularly in younger patients, and in those without previous cardiovascular disease.

\section{INTRODUCTION}

Most patients with acute myocardial infarction (AMI) present with chest pain, ${ }^{1}$ but presenting without classical symptoms is not uncommon. Previous studies have shown that between $10 \%$ and $40 \%$ of patients with AMI do not report chest pain. ${ }^{1-5}$ Absence of chest pain in AMI is more common in patients with a history of diabetes, in women, older patients ${ }^{67}$ and in patients with non ST-segment-elevation myocardial infarction

\section{Key questions}

What is already known about this subject?

- Chest pain is the most common symptom in patients with acute myocardial infarction (AMI), but presenting without typical symptoms is not uncommon. The absence of chest pain is known to be associated with higher age, female sex and non ST-segmentelevation myocardial infarction, and also with more complications and significantly higher short-term mortality compared with patients presenting with chest pain.

What does this study add?

- This large study included all patients aged 18 to 84 years in the SWEDEHEART registry, who were admitted to hospital because of AMI between 1996 and 2010. The study adds new information demonstrating that absence of chest pain in patients with AMI is associated with more complications and higher short-term and also long-term mortality, especially in younger patients, with few comorbidities.

How might this impact on clinical practice?

- Patients with AMI who present without classical chest pain are a vulnerable group and should be targeted in order to decrease potentially avoidable mortality, short-term as well as long-term.

(non-STEMI) ${ }^{8}$ Patients with AMI with insidious, vague or atypical symptoms have difficulties in interpreting and acknowledging bodily symptoms. ${ }^{9-12}$ Moreover, atypical symptoms of AMI are associated with significantly higher mortality ${ }^{513-15}$ for reasons that are not entirely clear.

Patients with AMI presenting without chest pain have a longer delay before they seek medical attention and hospital presentation. ${ }^{7}$ Therefore, these patients are more frequently misdiagnosed ${ }^{516}$ and receive less aggressive medical treatments and interventions. ${ }^{5}$ Potentially because of this, complications are more prevalent in patients with AMI presenting without chest pain or discomfort than in those with these symptoms. Patients with AMI without chest pain have a 
higher short-term mortality rate compared with patients presenting with chest pain. ${ }^{13}$ However, whether this poorer outcome is sustained throughout the first year has only been shown in a small study. ${ }^{14}$ Therefore, this study aimed to investigate long-term mortality in patients who were hospitalised with AMI presenting with or without chest pain.

\section{METHODS}

\section{Registers and sample procedure}

We obtained information from the national quality of care register SWEDEHEART. ${ }^{17}$ The register includes all patients who are treated for acute coronary syndrome in coronary care units or other specialised facilities in Sweden. The register started in 1995 with 19 participating hospitals, increasing gradually to 72 hospitals, and currently includes all Swedish hospitals treating acute cardiac diseases. The register includes information on clinical characteristics, type of infarction, symptoms, diagnosis, medication, and procedures on admission, during hospitalisation and at discharge. The register is monitored on a regular basis with a $95 \%-96 \%$ agreement between the registry and health records. On admission, all patients who are registered in SWEDEHEART receive written information about the registry, their voluntary participation and about the possibility to decline participation.

\section{Definitions}

During the study period, Sweden adhered to the criteria for diagnosis of AMI according to WHO (1996 to 2001) ${ }^{18}$ Additionally, criteria were based on the European Society of Cardiology and American College of Cardiology Committee/American Heart Association consensus document from 2001 when the use of troponins became standard. ${ }^{19}{ }^{20}$ Tobacco smoking status was defined as not smoking (never smoked), ex-smoker ( $>1$ month before admission to hospital) and current smoker.

This study included all patients aged 18 to 84 years in the SWEDEHEART registry, who were admitted to hospital because of AMI between 1996 and 2010. We included patients the first time that they appeared in the register, and a total of 194609 patients were identified. In the protocol, symptom presentation at the time of admission was registered as (1) chest pain, (2) dyspnoea, (3) prehospital cardiopulmonary resuscitation (CPR) or (4) other symptoms (not specified). Patients presenting with dyspnoea or other symptoms was defined as not having chest pain. Patients with missing information on symptom presentation ( $\mathrm{n}=19 \quad 422,10.0 \%)$, prehospital CPR $(\mathrm{n}=2158,1.12 \%)$ or invalid PIN codes $(\mathrm{n}=48,0.025 \%)$ were excluded from the study. After these exclusions, the study population comprised 172981 unique patients diagnosed with AMI. By merging the Swedish National Inpatient Register (IPR) with SWEDEHEART, prior events or a history of diabetes, hypertension, heart failure, stroke, percutaneous coronary intervention (PCI) and coronary artery bypass grafting (CABG) were identified. Data for the remaining baseline variables were collected from SWEDEHEART. The Swedish IPR is based on the International Classification of Diseases (ICD) codes, with the ICD ninth revision used from 1987 to 1997 and the ICD 10th revision from 1997 to 2010. Data regarding all-cause mortality were obtained by merging SWEDEHEART with the National Cause of Death register. For anonymity, all personal identifiers were removed and replaced with a code in the final data set.

\section{Statistical methods}

All analyses and data management were performed using the statistical software SAS V.9.3 (SAS Institute, Cary, North Carolina, USA). Graphics were created in R V.3.1.3. Descriptive statistics mean and SD, median and IQR and percentages are used to describe baseline characteristics. Comparison of risk factors between different groups at baseline was assessed by the $\chi^{2}$ test for dichotomous variables and the t-test for mean values, as well as the Wilcoxon rank test for medians of continuous variables. HRs with 95\% CIs were obtained from Cox regression to assess the relative risk of mortality over time for patients with AMI without chest pain relative to those with chest pain. Two different adjustment techniques were used for each time window; one model was adjusted for age and year of hospitalisation and the other for all covariates in the list. The incidence rate for death was calculated as the ratio of events (death) and person-years of follow-up for all patients. The rates were calculated for the age groups 18 to 64 and 65 to 84 years by symptom presentation. All-cause mortality and 30-day, 1-year and 5-year mortality rates were calculated within each age group in relation to presentation of symptoms. The 5-year survival functions were estimated by the Kaplan-Meier method. The log-rank test was conducted to compare survival at 30 days, 1 year and 5 years between patients with AMI presenting with or without chest pain. Significance level was set at $p$ value $<0.05$.

\section{RESULTS}

A total of 172981 patients were included in the study cohort; of these, $33.5 \%(n=57914)$ were women. Women with AMI were significantly older than men (71.5, SD 10.2 vs 67.1 years, SD 11.0, $\mathrm{p}<0.001)$. The majority of patients presented with chest pain: $92.9 \%$ in patients $<65$ years and $84.4 \%$ in those $\geq 65$ years (data not shown). The proportion of patients presenting without chest pain was significantly higher in women than in men $(16.2 \%$ vs $11.0 \%, \mathrm{p}<0.001)$. This proportion increased with age, such that $5.5 \%$ and $4.7 \%$ of women and men aged 18-44 years had no chest pain compared with $20.0 \%$ and $16.8 \%$ of women and men aged $75-84$ years, respectively (table 1). In those presenting without chest pain, 25.1\% and $29.6 \%$, respectively, among younger $(<65$ years) and older patients ( $\geq 65$ years) had dyspnoea, while the rest had other symptoms (data not shown). 
Table 1 Number and proportion of women and men with acute myocardial infarction presenting with or without chest pain by age group

\begin{tabular}{|c|c|c|c|c|}
\hline \multirow[b]{2}{*}{ Age group (years) } & \multicolumn{2}{|l|}{$\begin{array}{l}\text { Women } \\
(n=57 \text { 914) }\end{array}$} & \multicolumn{2}{|l|}{$\begin{array}{l}\text { Men } \\
(n=115067)\end{array}$} \\
\hline & Without chest pain & With chest pain & Without chest pain & With chest pain \\
\hline Total & 9361 (16.2) & $48553(83.8)$ & $12630(11.0)$ & $102437(89.0)$ \\
\hline $18-44$ & $54(5.5)$ & $920(94.5)$ & $156(4.7)$ & 3133 (95.3) \\
\hline $45-54$ & $264(7.4)$ & 3289 (92.6) & $646(4.8)$ & 12775 (95.2) \\
\hline $55-64$ & 991 (11.2) & 7862 (88.8) & $2046(7.2)$ & $26352(92.8)$ \\
\hline $65-74$ & 2480 (14.9) & $14131(85.1)$ & 3868 (11.2) & $30818(88.8)$ \\
\hline 75-84 & $5572(20.0)$ & 22351 (80.0) & 5914 (16.8) & 29359 (83.2) \\
\hline
\end{tabular}

Patients with AMI presenting without chest pain were older, more often women, and had more risk factors (diabetes, hypertension) and comorbidities, regardless of age, compared with patients presenting with chest pain. Smoking was more common in patients $<65$ years and significantly higher in those presenting with chest pain. Additionally, previous medication with aspirin, $\beta$-blockers, ACE inhibitors/angiotensin receptor blockers, lipid-lowering treatment and diuretics were more common in in both younger and older patients without chest pain, especially in older patients (table 2).

Overall median (IQR) concentrations of maximum troponin $\mathrm{T}$ and troponin I were higher in patients presenting with chest pain. In patients without chest pain, median (IQR) concentrations of maximum troponin $\mathrm{T}$ and troponin I were higher in older patients (table 2). The proportion of patients with STEMI was significantly higher in patients with chest pain and notably higher in younger patients. Also, the median (IQR) delay from symptom onset to hospitalisation was longer in patients without chest pain. Patients without chest pain had a higher mean heart rate on admission, but lower mean systolic blood pressure. Overall, patients with AMI without chest pain had more complications, regardless of age, and were more likely to present with signs of heart failure (pulmonary rales) and had more prehospital treatment with continuous positive airway pressure (table 2 ).

In patients with AMI aged $<65$ years with chest pain, $1.9 \%$ died within 30 days compared with $7.3 \%$ of those presenting without chest pain. Corresponding percentages in patients aged $\geq 65$ years presenting with or without chest pain were $8.7 \%$ and $16.4 \%$, respectively. After 5 years, $7.9 \%$ and $25.5 \%$, respectively, of patients aged $<65$ years presenting with and without chest pain had died. Corresponding percentages in patients aged $\geq 65$ years were $34 \%$ and $57.7 \%$, respectively (table 2 ).

\section{Procedures, treatments and clinical characteristics}

Serious complications during hospitalisation were more prevalent in patients with AMI presenting without chest pain, particularly in younger patients. In younger patients without chest pain, $7.1 \%$ required CPR and $8.1 \%$ received inotropic support (table 3). Furthermore, patients without chest pain were also less likely to undergo angiography regardless of age. Patients aged $<65$ years with chest pain had the lowest rate of serious complications during hospitalisation (requirement for CPR, 2.7\%; inotropic support, 2.3\%) and also received more treatment with aspirin/antiplatelets (94\%), $\beta$-blockers (91.8\%) and statins $(79.4 \%)$. Treatment with diuretics was markedly higher in younger patients without chest pain, as was treatment with ACE inhibitors/angiotensin receptor blockers and calcium blockers compared with those with chest pain. Overall, patients aged $\geq 65$ years without chest pain received less medication but more treatment with ACE inhibitors/angiotensin receptor blockers compared with patients with chest pain. In addition, treatment with diuretics was markedly higher, with approximately three of four patients treated (table 3 ).

\section{Mortality rate}

Figure $1 \mathrm{~A}$ and $\mathrm{B}$ shows that most of the excess mortality associated with lack of chest pain occurred in the short term, but with a widening gap throughout the 5-year follow-up. Overall, absence of chest pain was associated with a 5-year mortality HR of 2.12 (95\% CI 2.07 to 2.16$)$ (figure 2). In patients with AMI presenting without chest pain compared with those with chest pain, the HRs for mortality, after adjustment for age and year of hospitalisation, were somewhat greater in men than in women (men: HR 2.23, 95\% CI 2.16 to 2.29; women: HR 2.00, $95 \%$ CI 1.94 to 2.07$)$ and higher in younger than in older patients ( $<65$ years: HR $3.60,95 \%$ CI 3.36 to $3.85 ; \geq 65$ years: HR 2.02, 95\% CI 1.97 to 2.06). However, the HRs were slightly lower in patients with prior hypertension, diabetes, heart failure, AMI and stroke (all $\mathrm{p}$ values for interaction $<0.001)$. HRs associated with absence of chest pain increased over time from 1.97 (95\% CI 1.89 to 2.05 ) from 1996 to 2000 to 2.31 (95\% CI 2.22 to 2.39 ) in 2006 to 2010 ( $\mathrm{p}$ values for interaction $<0.001$ ). Interactions between absence/presence of chest pain and smoking $(\mathrm{p}=0.0236)$ and period $(\mathrm{p}=0.0017)$ were weaker. The 30-day and 1-year risk of mortality showed a similar pattern as the 5-year follow-up, except for smoking (online supplementary figures 1-4). After multivariable adjustments, the HRs for 5-year mortality decreased but 
Table 2 Baseline characteristics in 172981 women and men with acute myocardial infarction by age group and symptom presentation

\begin{tabular}{|c|c|c|c|c|}
\hline & \multicolumn{2}{|l|}{$<65$ years $^{*} n=58488$} & \multicolumn{2}{|l|}{$\geq 65$ years $\dagger n=114493$} \\
\hline & $\begin{array}{l}\text { Without chest pain } \\
\mathrm{n}=4157\end{array}$ & $\begin{array}{l}\text { With chest pain } \\
n=54331\end{array}$ & $\begin{array}{l}\text { Without chest pain } \\
n=17834\end{array}$ & $\begin{array}{l}\text { With chest pain } \\
\mathrm{n}=96659\end{array}$ \\
\hline Age, years, mean SD & $57.1 \pm 6.4$ & $55.6 \pm 6.8$ & $76.3 \pm 5.4$ & $74.9 \pm 5.6$ \\
\hline Women, n (\%) & $1309(31.5)$ & $12071(22.2)$ & $8052(45.1)$ & $36482(37.7)$ \\
\hline \multicolumn{5}{|l|}{ Risk factors } \\
\hline Current smoker, n (\%) & $1541(37.1)$ & $22588(41.6)$ & $2706(15.2)$ & $13879(14.4)$ \\
\hline Diabetes, $n(\%)$ & $1359(32.7)$ & $9573(17.6)$ & $5606(31.4)$ & $22156(22.9)$ \\
\hline Hypertension, $\mathrm{n}(\%)$ & $1741(41.9)$ & $17953(33.0)$ & $9235(51.8)$ & $46025(47.6)$ \\
\hline \multicolumn{5}{|l|}{ Cardiovascular disease history } \\
\hline Myocardial infarction, n (\%) & $693(16.7)$ & $6029(11.1)$ & $4689(26.3)$ & $23554(24.4)$ \\
\hline $\begin{array}{l}\text { Cardiac intervention, } n(\%) \\
\text { (CABG/PCI) }\end{array}$ & $420(10.1)$ & $4506(8.3)$ & $1797(10.1)$ & $11714(12.1)$ \\
\hline Heart failure, $n(\%)$ & 509 (12.2) & $1699(3.1)$ & $4608(25.8)$ & $13065(13.5)$ \\
\hline Stroke, $n(\%)$ & $368(8.9)$ & $2157(4.0)$ & $3530(19.8)$ & $12433(12.9)$ \\
\hline \multicolumn{5}{|l|}{ Medication } \\
\hline Aspirin/antiplatelets, n (\%) & $1247(30.0)$ & $10743(19.8)$ & $7870(44.1)$ & $39732(41.1)$ \\
\hline$\beta$-blocker, n (\%) & $1354(32.6)$ & $12456(22.9)$ & $7082(39.7)$ & $36488(37.7)$ \\
\hline ACE inhibitor/ARB, \% (n) & $1135(27.3)$ & $8856(16.3)$ & $5729(32.1)$ & $23815(24.6)$ \\
\hline Statins, n (\%) & $1012(24.3)$ & $8802(16.2)$ & $3858(21.6)$ & $18861(19.5)$ \\
\hline Calcium blocker, n (\%) & $533(12.8)$ & $5705(10.5)$ & $3078(17.3)$ & $18206(18.8)$ \\
\hline Diuretics, n (\%) & $899(21.6)$ & $5053(9.3)$ & $7260(40.7)$ & 27679 (28.6) \\
\hline \multicolumn{5}{|l|}{ Variables recorded at admission } \\
\hline Presence of pulmonary rales, $\mathrm{n}(\%)$ & $1091(26.2)$ & $3817(7.0)$ & $7370(41.3)$ & $18914(19.6)$ \\
\hline LBBB, n (\%) & $281(6.8)$ & $1146(2.1)$ & $2451(13.7)$ & $6806(7.0)$ \\
\hline RBBB, $n(\%)$ & $86(2.1)$ & $634(1.2)$ & $611(3.4)$ & $2315(2.4)$ \\
\hline STEMI, n (\%) & $892(21.5)$ & $24617(45.3)$ & $2987(16.7)$ & $34815(36.0)$ \\
\hline Prehospital CPAP, n (\%) & $474(11.4)$ & $775(1.4)$ & $3233(18.1)$ & $3782(3.9)$ \\
\hline Delay time, min, median (IQR) & $225(83-930)$ & $165(85-425)$ & $210(87-760)$ & $195(100-475)$ \\
\hline $\begin{array}{l}\text { Systolic blood pressure, mm Hg, mean } \\
\text { (SD) }\end{array}$ & $143.4 \pm 33.3$ & $146.6 \pm 27.7$ & $142.1 \pm 33.0$ & $147.6 \pm 29.3$ \\
\hline Heart rate, beats/min, mean (SD) & $92.3 \pm 29.4$ & $76.4 \pm 19.3$ & $93.6 \pm 28.6$ & $78.9 \pm 22.4$ \\
\hline Troponin I, $\mu / L$, median (IQR) & $2.8(0.66-11.3)$ & $5.0(0.85-24.0)$ & $3.18(0.81-11.2)$ & $4.86(0.97-22.0)$ \\
\hline Troponin $\mathrm{T}, \mu / \mathrm{L}$, median (IQR) & $0.51(0.18-1.77)$ & $1.0(0.26-3.21)$ & $0.59(0.20-1.98)$ & $0.95(0.26-3.05)$ \\
\hline \multicolumn{5}{|l|}{ Outcomes } \\
\hline 30-day mortality, $n(\%)$ & $303(7.3)$ & $1035(1.9)$ & $2928(16.4)$ & $8410(8.7)$ \\
\hline Per 1000 person-years & 945 & 236 & 2294 & 1140 \\
\hline 1-year mortality, n (\%) & $615(14.8)$ & $1989(3.7)$ & $5830(32.7)$ & $16163(16.7)$ \\
\hline Per 1000 person-years & 175 & 39 & 452 & 199 \\
\hline 5-year mortality, n (\%) & $1061(25.5)$ & 4292 (7.9) & $10292(57.7)$ & $32899(34.0)$ \\
\hline Per 1000 person-years & 83 & 21 & 259 & 109 \\
\hline
\end{tabular}

*All $p$ values, when comparing patients $<65$ years presenting without and with chest pain, $<0.001$.

${ }^{\dagger}$ All $p$ values, when comparing patients $\geq 65$ years presenting without and with chest pain, $<0.001$, except for smoking $p=0.0045$.

$\mathrm{AMI}$, acute myocardial infarction; ARB, angiotensin receptor blocker; CABG, coronary artery bypass grafting; CPAP, continuous positive airway pressure; LBBB, left bundle branch block; PCI, percutaneous coronary intervention; RBBB, right bundle branch block; STEMI ST, STsegment-elevation myocardial infarction. 
Table 3 Procedures and hospital treatment in patients with acute myocardial infarction by age group and symptom presentation

\begin{tabular}{|c|c|c|c|c|}
\hline & \multicolumn{2}{|l|}{$<65$ years $n=54488$} & \multicolumn{2}{|c|}{$\geq 65$ years $n=114493$} \\
\hline & $\begin{array}{l}\text { Without chest pain } \\
n=4157\end{array}$ & $\begin{array}{l}\text { With chest pain } \\
n=54331\end{array}$ & $\begin{array}{l}\text { Without chest pain } \\
n=17834\end{array}$ & $\begin{array}{l}\text { With chest pain } \\
\mathrm{n}=96659\end{array}$ \\
\hline Angiography, $\mathrm{n}(\%)$ & 2279 (54.8) & $34670(63.8)$ & $4815(27.0)$ & $42844(44.3)$ \\
\hline Thrombolysis, n (\%) & $275(6.6)$ & $11042(20.3)$ & $633(3.6)$ & 16767 (17.4) \\
\hline Cardiac intervention (CABG/PCI), n (\%) & $1404(33.8)$ & $29481(54.3)$ & $2836(15.9)$ & $33979(35.2)$ \\
\hline CPR, n (\%) & $297(7.1)$ & $1478(2.7)$ & $1152(6.5)$ & $4110(4.3)$ \\
\hline Inotropic agents, n (\%) & $329(7.9)$ & $1259(2.3)$ & $1284(7.2)$ & $4042(4.2)$ \\
\hline LMWH, n (\%) & $2892(69.6)$ & $37097(68.3)$ & $10941(61.4)$ & $61679(63.8)$ \\
\hline Aspirin/antiplatelets, $n(\%)$ & 3520 (84.7) & $51080(94)$ & $13492(75.7)$ & $83515(86.4)$ \\
\hline$\beta$-blocker*, n (\%) & $3525(84.8)$ & $49865(91.8)$ & $13389(75.1)$ & $82165(85)$ \\
\hline ACE inhibitor/ARB, \% (n) & 2610 (62.8) & $28580(52.6)$ & $10061(56.4)$ & $53293(55.1)$ \\
\hline Statins, n (\%) & $2922(70.3)$ & $43151(79.4)$ & 8659 (48.6) & $59108(61.2)$ \\
\hline Calcium blocker, n (\%) & $510(12.3)$ & $5271(9.7)$ & 2296 (12.9) & $14419(14.9)$ \\
\hline Diuretics*, n (\%) & $2127(51.2)$ & $11334(20.9)$ & $12843(72)$ & 47589 (49.2) \\
\hline
\end{tabular}

*Oral and/or intravenously.

$\mathrm{AMI}$, acute myocardial infarction; ARB, angiotensin receptor blocker; CABG, coronary artery bypass grafting; CPR, cardiopulmonary resuscitation; LMWH, low molecular weight heparin; $\mathrm{PCl}$, percutaneous coronary intervention.

were still higher in patients without chest pain compared with those with chest pain, with no significant interaction with sex (figure 3). However, all interactions between an absence/presence of chest pain and age, hypertension, diabetes and prior disease were still highly significant, with stronger effects in younger subjects and in those without prior known risk factors and cardiovascular disease.

\section{DISCUSSION}

The main aim of this study was to compare the longterm mortality between patients with AMI presenting with or without chest pain. Our study, which included a large number of patients with AMI, showed that patients presenting without chest pain had a higher short-term mortality rate and also had more complications. Additionally, patients without chest pain had a markedly
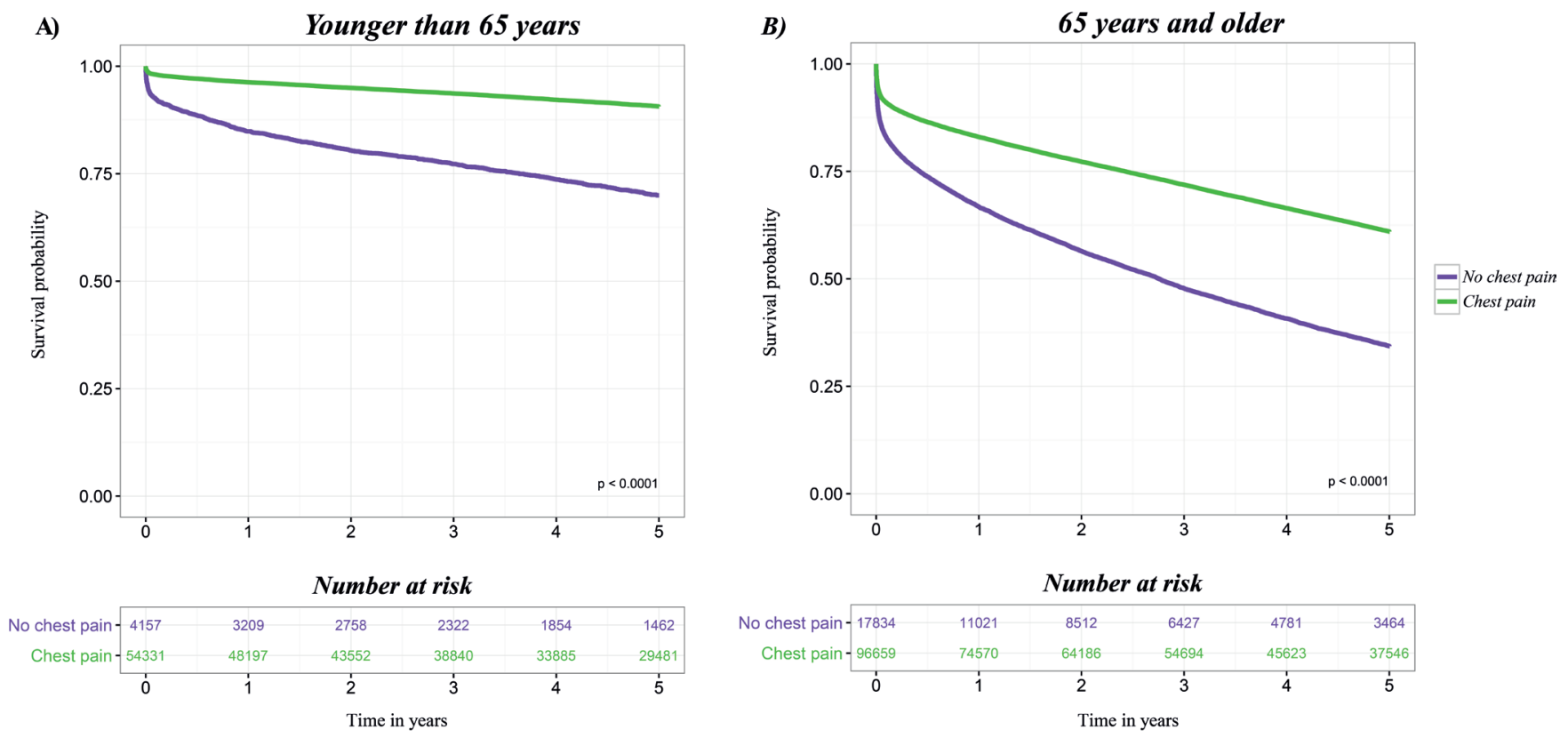

Figure 1 (A, B) Survival probability curves for patients with acute myocardial infarction presenting with or without chest pain by age group. 
5 years HR for AMI patients without chest pain

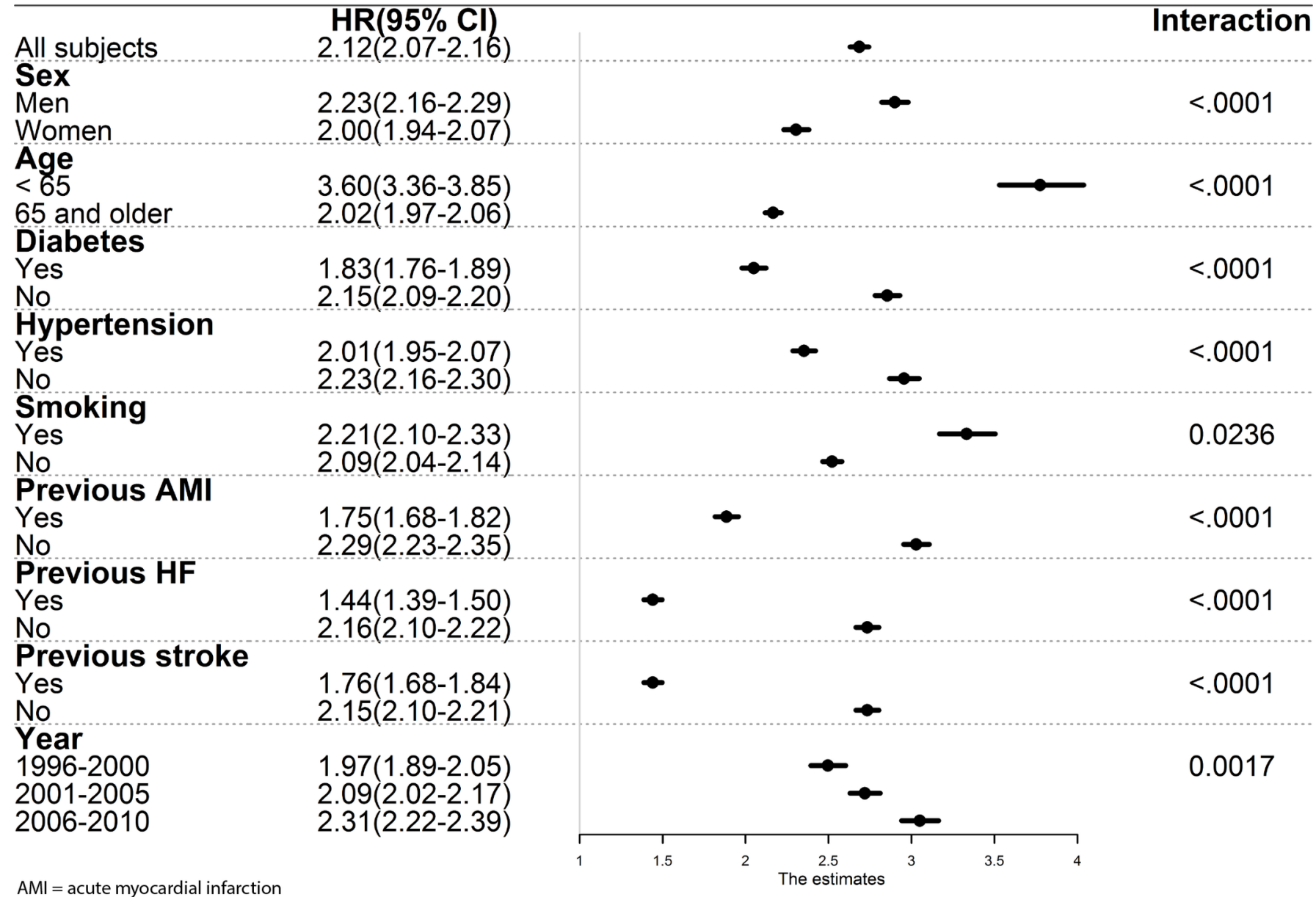

$\mathrm{HF}=$ heart failure

Figure 2 HRs adjusted for age (years) and year of hospitalisation for 5-year mortality in patients with AMI presenting with or without previous hypertension, diabetes, cardiovascular disease and smoking.

higher relative long-term mortality, especially in younger patients, and in those who were comparatively healthy before admission, compared with those with chest pain.

Long-term mortality, in absolute terms, in patients presenting without chest pain was markedly high in our study. More than a quarter of patients aged $<65$ years and half of those aged $\geq 65$ years died over the 5 -year follow-up. To the best of our knowledge, few previous studies have investigated long-term mortality in patients with AMI presenting with or without chest pain. Our study confirms the finding from a small single-centre German study ${ }^{14}$ that showed that absence of chest pain was associated with an $85 \%$ higher risk of long-term mortality, but that study did not report age-specific estimates. In our study, the shortterm mortality (30 days) in patients with AMI presenting without chest pain was $7.3 \%$ and $16.4 \%$ in younger and older patients, respectively, in line with a US study ${ }^{13}$ that showed that in-hospital mortality in patients presenting without chest pain ranged from $12.5 \%$ to $16.1 \%$ in men and women aged up to 64 years and approximately $22 \%$ in patients aged $65-84$ years.

In the present study, chest pain was absent in $11.0 \%$ of men and $16.2 \%$ of women. Some studies have suggested that absence of chest pain is more common and present in approximately $30 \%-40 \%$ of all patients with myocardial infarction. ${ }^{67}$ Other studies have shown that chest pain is present in approximately $90 \%$ of all cases, ${ }^{1414}$ but that women to a higher extent have more other associated symptoms. ${ }^{1414}$ These differences could be explained by inconsistencies in the definition of chest pain between different studies. ${ }^{6}$ However, in the present study, the same protocol was used throughout the whole study period with no changes in the definition of symptoms related to AMI.

Patients with AMI presenting without chest pain were less likely to undergo angiography and to undergo cardiac intervention (PCI or CABG) which also could explain the poorer outcome since early angiography followed by revascularisation has been shown to prevent recurrent ischaemia and improve outcome in patients with non-STEMI ${ }^{21}$ as well as in those with STEMI. ${ }^{22}$ Even though conditions such as diabetes, hypertension, AMI, stroke and heart failure were more prevalent in patients with AMI presenting without chest pain, medical treatment with aspirin, $\beta$-blockers and lipid-lowering treatment were markedly lower during hospitalisation/at 
5 years HR for AMI patients without chest pain - multiadjusted

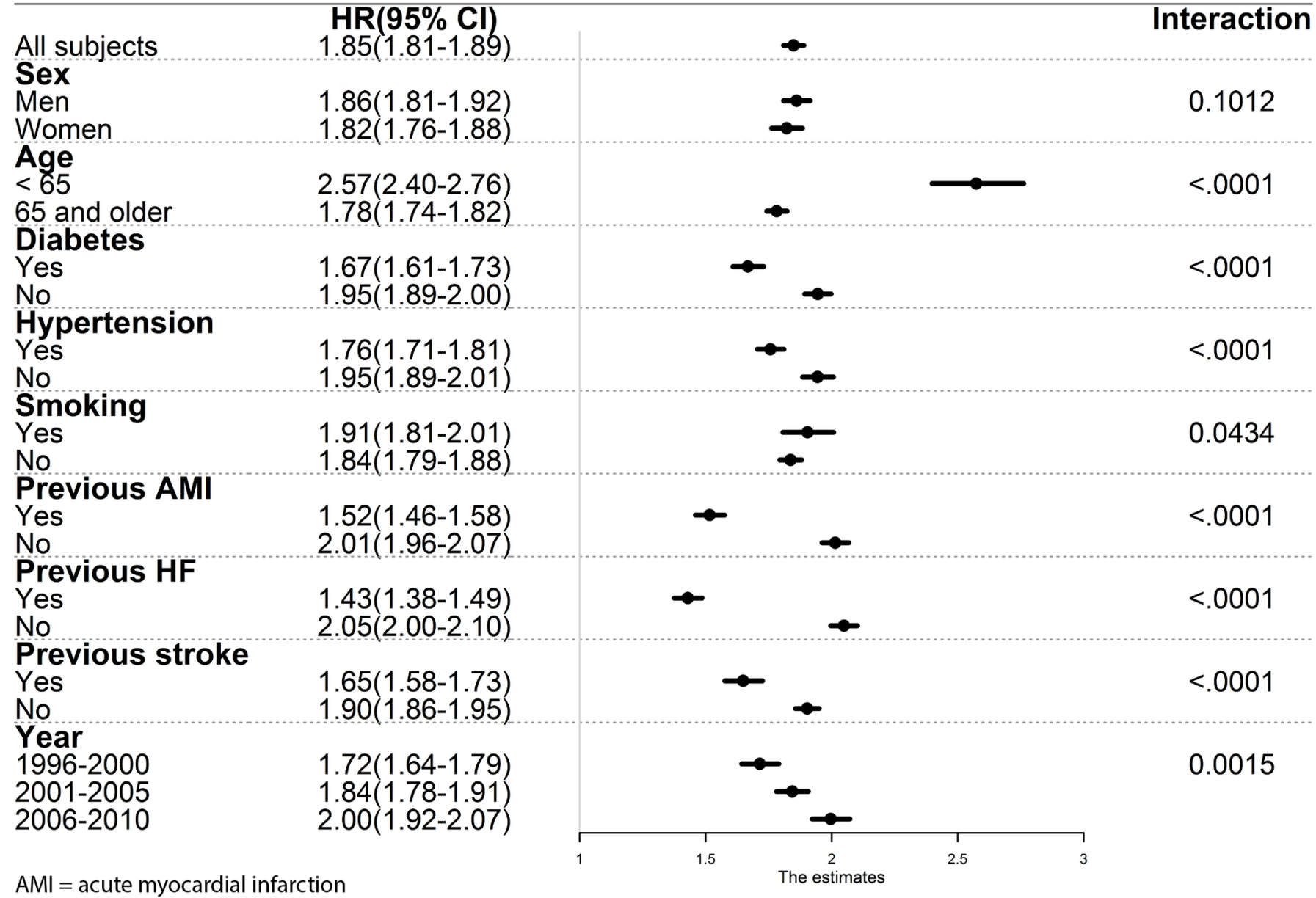

$\mathrm{HF}=$ heart failure

Figure 3 Multiple adjusted HRs for 5-year mortality in patients with AMI presenting without chest pain with or without previous hypertension, diabetes, cardiovascular disease and smoking. HRs were adjusted for age (years), year of hospitalisation and all covariates in the list.

discharge compared with those with chest pain, which might have contributed to the poorer outcome. A previous study showed that 30-day mortality in patients with AMI was significantly lower in Sweden compared with the UK. This finding was mainly explained by more extensive use of PCI in patients with STEMI, but also by treatment with $\beta$-blockers at discharge, regardless of the type of AMI. ${ }^{23}$ Evidence-based treatments with aspirin/ antiplatelet, $\beta$-blockers and statins in the acute phase and in secondary prevention after AMI are associated with a lower risk of reinfarction and lower mortality. ${ }^{24} 25$ These findings emphasise that treatment should be performed according to guidelines, however carefully judging the benefit in each individual case.

Previous studies have shown that patients with AMI without chest pain or atypical symptoms delay longer before seeking medical attention, which also was the case in this study and could explain why they experience more complications. Moreover, failure to identify symptoms as associated with AMI is associated with worse outcome. ${ }^{516}$ Absence of chest pain was associated with higher age, female sex and higher 5-year mortality. Additionally, in patients with AMI presenting without chest pain, hypertension, diabetes and previous cardiovascular disease (AMI, heart failure, stroke) were associated with significantly lower HRs. This could potentially be explained by increased awareness of cardiovascular disease in patients with risk factors or those who have already manifested cardiovascular disease. ${ }^{26}{ }^{27} \mathrm{In}$ addition, previous medication could also be protective. We have previously shown that patients treated with aspirin, $\beta$-blockers, ACE inhibitors and statins before hospitalisation for AMI had a lower risk of presenting with STEMI. ${ }^{28}$ However, patients without chest pain might represent a subset with subclinical cardiovascular conditions, explaining their higher absolute and relative risks.

The study has several strengths as well as limitations. Among the strengths, first, this study included data on a large population of patients hospitalised with AMI and included in the national quality of care register, SWEDEHEART, in Sweden between 1996 and 2010. SWEDEHEART has national coverage and all hospitals with acute cardiac care in Sweden are included in this register. Second, SWEDEHEART was linked to the Swedish IPR, 
with national coverage, which includes nationwide data on previous hospitalisations for AMI, PCI/CABG, heart failure and stroke. The Swedish IPR has been validated against patient records, and shows high validity, especially for major cardiovascular diagnoses ${ }^{29}$; however, subtypes of AMI such as type 2 infarction could not be distinguished, nor takutsubo syndrome which might have been confused with AMI in rare cases. Third, our study included a long-term follow-up linking SWEDEHEART to the national Cause of Death register with almost complete coverage to obtain information on deaths during the follow-up. However, there are also some limitations as in other registry studies. Symptom presentation is recorded as chest pain, dyspnoea, prehospital CPR and other symptoms. But other symptoms are not specified and there is a lack of a precise characterisation of symptoms, which is a limitation to the present study. Because presentation of symptoms is less reliable in patients requiring prehospital CPR, those individuals were excluded from the study, which is, however, unlikely to have influenced the results because they represented only $1.1 \%$ of exclusions. The current study was limited to variables that have been consistent and uniformly recorded since the start of the register. Because the definition of cardiogenic shock changed during the study period (1996-2010), this variable was not included. This could potentially have led to underestimation of the risk of mortality in patients presenting without chest pain. Also, even though HRs for mortality were adjusted for age, sex, year of hospitalisation, smoking and prior disease, there is a potential risk of residual confounding.

\section{CONCLUSION}

Absence of chest pain in patients with AMI is associated with more complications and higher short-term and longterm mortality rates, especially in younger and healthier patients, even after taking other relevant factors into consideration. A higher awareness in identifying patients with AMI, despite an absence of symptom, is needed, as well as more intense treatment in the acute phase and during hospitalisation, and at discharge for these patients.

Contributors Substantial contributions to the conception or design of the work, or the acquisition, analysis or interpretation of the data for the work: LB, SN, TJ, TZ-S, KWG, AR. Drafting of the work or revising it critically for important intellectual content: LB, SN, TJ, TZ-S, KWG, AR. Final approval of the version to be published: LB, SN, TJ, TZ-S, KWG, AR. Agreement to be accountable for all aspects of the work in ensuring that questions related to the accuracy or integrity of any part of the work are appropriately investigated and resolved: LB, SN, TJ, TZ-S, KWG, AR.

Funding This study received grants from the Swedish State under the Agreement Concerning Research and Education of Doctors (ALFGBG-427301); the Swedish Heart and Lung Foundation (2015-0438); the Swedish Research Council (20135187 (SIMSAM), 2013-4236); and the Swedish Council for Health, Working Life and Welfare (FORTE) (Epilife).

\section{Competing interests None declared.}

Patient consent for publication Not required.

Ethics approval The Uppsala University Hospital ethics committee.

Provenance and peer review Not commissioned; externally peer reviewed.
Data sharing statement The data that we have acquired from a combination of registers cannot be shared, but they are accessible after relevant permissions from an ethics board and application to the registers in question.

Open access This is an open access article distributed in accordance with the Creative Commons Attribution Non Commercial (CC BY-NC 4.0) license, which permits others to distribute, remix, adapt, build upon this work non-commercially, and license their derivative works on different terms, provided the original work is properly cited, appropriate credit is given, any changes made indicated, and the use is non-commercial. See: https://creativecommons.org/licenses/by-nc/4.0/

\section{REFERENCES}

1. Berg J, Björck L, Dudas K, et al. Symptoms of a first acute myocardial infarction in women and men. Gend Med 2009;6:454-62.

2. Kirchberger I, Heier M, Wende R, et al. The patient's interpretation of myocardial infarction symptoms and its role in the decision process to seek treatment: the MONICA/KORA Myocardial Infarction Registry. Clin Res Cardiol 2012;101:909-16.

3. DeVon HA, Zerwic JJ. Symptoms of acute coronary syndromes: are there gender differences? A review of the literature. Heart Lung 2002;31:235-45.

4. Alconero-Camarero AR, Muñoz-Cacho P, Revuelta JM. Gender similarities and differences in the presentation of symptoms in acute myocardial infarction. Int J Cardiol 2013;168:2968-9.

5. Brieger D, Eagle KA, Goodman SG, et al. Acute coronary syndromes without chest pain, an underdiagnosed and undertreated high-risk group: insights from the Global Registry of Acute Coronary Events. Chest 2004;126:461-9.

6. Canto JG, Goldberg RJ, Hand MM, et al. Symptom presentation of women with acute coronary syndromes: myth vs reality. Arch Intern Med 2007;167:2405-13.

7. Canto JG, Shlipak MG, Rogers WJ, et al. Prevalence, clinical characteristics, and mortality among patients with myocardial infarction presenting without chest pain. JAMA 2000;283:3223-9.

8. Canto AJ, Kiefe Cl, Goldberg RJ, et al. Differences in symptom presentation and hospital mortality according to type of acute myocardial infarction. Am Heart J 2012;163:572-9.

9. Gyberg A, Björck L, Nielsen S, et al. Women's help-seeking behaviour during a first acute myocardial infarction. Scand J Caring Sci 2016;30:670-7.

10. Isaksson RM, Brulin C, Eliasson M, et al. Older women's prehospital experiences of their first myocardial infarction. $J$ Cardiovasc Nurs 2013;28:360-9.

11. Nielsen S, Falk K, Gyberg A, et al. Experiences and actions during the decision making process among men with a first acute myocardial infarction. J Cardiovasc Nurs 2015;30:332-9.

12. Kenyon LW, Ketterer MW, Gheorghiade M, et al. Psychological factors related to prehospital delay during acute myocardial infarction. Circulation 1991;84:1969-76.

13. Canto JG, Rogers WJ, Goldberg RJ, et al. Association of age and sex with myocardial infarction symptom presentation and in-hospital mortality. JAMA 2012;307:813-22.

14. Kirchberger I, Heier M, Kuch B, et al. Presenting symptoms of myocardial infarction predict short- and long-term mortality: the MONICA/KORA Myocardial Infarction Registry. Am Heart $J$ 2012;164:856-61.

15. Williams K, Monroe HM. Cardiovascular disease risk prediction factors. JAMA 2012;308:1969-70.

16. Pope JH, Aufderheide TP, Ruthazer R, et al. Missed diagnoses of acute cardiac ischemia in the emergency department. N Engl $\mathrm{J}$ Med 2000;342:1163-70

17. Jernberg T, Attebring MF, Hambraeus K, et al. The Swedish Websystem for enhancement and development of evidence-based care in heart disease evaluated according to recommended therapies (SWEDEHEART). Heart 2010;96:1617-21.

18. Tunstall-Pedoe $\mathrm{H}$, Kuulasmaa $\mathrm{K}$, Amouyel $\mathrm{P}$, et al. Myocardial infarction and coronary deaths in the World Health Organization MONICA Project. Registration procedures, event rates, and casefatality rates in 38 populations from 21 countries in four continents. Circulation 1994;90:583-612.

19. Myocardial infarction redefined-a consensus document of The Joint European Society of Cardiology/American College of Cardiology Committee for the redefinition of myocardial infarction. Eur Heart $J$ 2000;21:1502-13.

20. Alpert JS, Thygesen K, Antman E, et al. Myocardial infarction redefined-a consensus document of The Joint European Society of Cardiology/American College of Cardiology Committee for the redefinition of myocardial infarction. J Am Coll Cardiol 2000;36:959-69. 
21. Yan AT, Yan RT, Tan M, et al. In-hospital revascularization and oneyear outcome of acute coronary syndrome patients stratified by the GRACE risk score. Am J Cardiol 2005;96:913-6.

22. Szummer K, Wallentin L, Lindhagen L, et al. Improved outcomes in patients with ST-elevation myocardial infarction during the last 20 years are related to implementation of evidence-based treatments: experiences from the SWEDEHEART registry 1995-2014. Eur Heart J 2017;38:3056-65.

23. Chung SC, Gedeborg R, Nicholas O, et al. Acute myocardial infarction: a comparison of short-term survival in national outcome registries in Sweden and the UK. Lancet 2014;383:1305-12.

24. Hamm CW, Bassand JP, Agewall S, et al. ESC Guidelines for the management of acute coronary syndromes in patients presenting without persistent ST-segment elevation: The Task Force for the management of acute coronary syndromes (ACS) in patients presenting without persistent ST-segment elevation of the European Society of Cardiology (ESC). Eur Heart $J$ 2011;32:2999-3054.

25. Ibanez B, James S, Agewall S, et al. 2017 ESC Guidelines for the management of acute myocardial infarction in patients presenting with ST-segment elevation: The Task Force for the management of acute myocardial infarction in patients presenting with ST-segment elevation of the European Society of Cardiology (ESC). Eur Heart $J$ 2018;39:119-77.

26. Piepoli MF, Hoes AW, Agewall S. 2016 European Guidelines on cardiovascular disease prevention in clinical practice: The Sixth Joint Task Force of the European Society of Cardiology and Other Societies on Cardiovascular Disease Prevention in Clinical Practice (constituted by representatives of 10 societies and by invited experts): developed with the special contribution of the European Association for Cardiovascular Prevention \& Rehabilitation (EACPR). Eur J Prev Cardiol 2016;2016:Np1-96.

27. Karjalainen T, Adiels M, Björck L, et al. An evaluation of the performance of SCORE Sweden 2015 in estimating cardiovascular risk: the Northern Sweden MONICA Study 1999-2014. Eur J Prev Cardiol 2017;24:103-10.

28. Björck L, Wallentin L, Stenestrand U, et al. Medication in relation to ST-segment elevation myocardial infarction in patients with a first myocardial infarction: Swedish Register of Information and Knowledge About Swedish Heart Intensive Care Admissions (RIKSHIA). Arch Intern Med 2010;170:1375-81.

29. Ludvigsson JF, Andersson E, Ekbom A, et al. External review and validation of the Swedish national inpatient register. BMC Public Health 2011;11:450. 